\title{
The Impact of Positive Discipline on English Enlightenment among 3-4-year old Preschoolers
}

\author{
Huanhuan Ren ${ }^{1, a}$, Chi Ma ${ }^{2, b}$ \\ ${ }^{1}$ Teaching and Research Institute of Foreign Languages, Bohai University, Jinzhou, 121013, China \\ ${ }^{2}$ Jinzhou Institute of Forestry Research, Jinzhou Forestry Bureau, Jinzhou, 121013, China \\ arenhuanhuan2014@163.com, ${ }^{\mathrm{b}}$ machi2014 @tom.com
}

Keywords: Impact; Positive Discipline; English Enlightenment; 3-4-year Old Children

\begin{abstract}
Positive discipline has the potential to change children education landscape across the globe, and hundreds of thousands of parents have already used the advice in positive discipline. The fact is evident that positive discipline has gained stream in children education with its unique characteristics and profound impact on learners, instructors and communities. It's advocated that the influence of positive discipline on English enlightenment among 3-4-year-old children be denoted from three areas, i.e., deep understanding and mutual respect, effective communication and problem solving skills, and encouragement instead of praise, so as to raise a child who is responsible, respectful, and resourceful through the process of language enlightenment. It's hoped that this thesis provides a useful reference for English enlightenment practice among young students.
\end{abstract}

\section{Introduction}

Positive discipline has been tested by time as a foundation for developing self-discipline, responsibility, cooperation, problem-solving skills and mutual respect in children, and hundreds of thousands of grown-ups have already used the advice and strategies in positive discipline working with children. Thus what's the implication of positive discipline on English enlightenment among 3-4-year-old children? How to raise a child who is responsible, respectful, and resourceful through the process of language enlightenment? This thesis is aimed at finding the answers of the questions, with view to the rise of positive discipline, rationales for positive discipline, the development of positive discipline, unique characteristics of positive discipline model and advantages of positive discipline. This paper is a summary of this research work, which hopefully provides a useful reference for English enlightenment practice among young students.

\section{The Emergence and Development of Positive Discipline}

The Rise of Positive Discipline. The positive discipline parenting and classroom management model is based on the work of Alfred Adler and Rudolf Dreikurs. It's Dr. Adler who first introduced the idea of parenting education to United States audiences in the 1920s[1]. It's found that the classroom techniques, which were initially introduced in Vienna in the early 1920s, were brought to the United States by Dr. Dreikurs in the late 1930s[2]. Treating children respectfully was highly advocated by Alfred Adler, and Dreikurs and Adler refer to the kind and firm approach to teaching and parenting as democratic[3]. Many other authors have carried on the parenting and classroom work of Alfred Adler. In the 1980's, Lynn Lott and Jane Nelsen attended a workshop facilitated by John Taylor[4], and Jane wrote and self-published Positive Discipline in 1981. Jane and Lynn later decided to collaborate on the book which is now titled, Positive Discipline for Teenagers in 1988, and began to teach parenting and classroom management skills experientially[5]. Lynn and Jane also wrote Positive Discipline in the Classroom and developed a manual filled with experiential activities for teachers and their students[6]. In the years since, Positive Discipline series has grown to include titles that address different age groups, family settings, and special situations[7]. Positive discipline is taught to schools, parents, and parent educators by trained certified positive discipline associates. Community members, parents, and teachers are encouraged to become trained facility[8]. 
The term positive discipline has become very popular and have sprang up and grabbed much spotlight in children education.

Rationales for Positive Discipline. A plethora of literature are in support of the use of positive discipline. Firstly, humanistic theory provides rationale for positive discipline utilized in the realm of education. Humanistic education is an approach to education which features person-centered teaching where empathy, caring about students, and genuineness on the part of the learning facilitator were found to be the key traits of the most effective teachers[9]. Positive discipline supports mutual respect among adults and children with more concern on the grow and development as a whole person. Secondly, many parenting books and programs that claim to be positive discipline are based on the philosophy of behaviorism. Behaviorism focuses on one particular view of learning, that is, a change in external behavior achieved through using reinforcement and repetition to shape behavior. However, positive discipline promotes "internal" locus of control, as opposed to "external" locus of control in the original Adlerian-based positive discipline[10]. Lastly, positive discipline has its root in theories of children development through impacting people differently from infants, toddlers to teenagers. Research has shown that the first three years in a child's life are a critical moment in their development, and that behavior patterns instilled during that time can have profound implications for the rest of a child's life[11]. Positive discipline is aimed at long-term results considering of what to do in the future to survive or to thrive in the early years of life.

The Development of Positive Discipline. Over the years millions of parents have used the amazingly effective strategies of positive discipline to raise happy, well-behaved, and successful children. The celebrated positive discipline brand of parenting books presents the revised and updated third edition of their readable and practical guide to communicating boundaries to very young children and solving early discipline problems to set children up for success. As well, for twenty-five years, the book of Positive Discipline has been sold to four million people in America and translated in sixteen language across the globe. It's regarded as the classic guide to helping children develop self-discipline, responsibility, cooperation, and problem-solving skills, and the gold standard reference for grown-ups working with children[12]. By pushing the idea that the best way to learn is to teach and the best way to teach is experientially[13], the positive discipline parent education and classroom management models were developed by Dr. Jane Nelsen and other people. Positive discipline parent education classes are taught across the globe, and every learner qualified for $13 \mathrm{CE}$ credits in the training are given certification for parent educators and teachers upon completion of the training[14]. People who can't find a workshop in their areas can take he independent study DVD training or online training. Moreover, positive discipline is successfully used as the classroom management model in private, religious, and public elementary schools[15].

\section{Characteristics and Advantages of Positive Discipline Model among 3-4-year-old Children}

Unique Characteristics of Positive Discipline Model. Positive discipline model is quite different from traditional learning and teaching paradigm, and some unique characteristics of positive discipline model are proposed by scholars[16]. Firstly, people are encouraged to teach adults and students through experiential activities. It makes sense to create opportunity to practice new skills and to have fun learning by doing. It turns out that less teacher wasted energy in dealing with misbehaved children in life. Secondly, classroom discipline programs and parent education programs that are consistent. Parents, teachers, and childcare providers can work together to provide a secure, consistent environment for children. In other words, they can instill valuable social and life skills and positive behavior inside and outside the home by using methods of positive discipline. Thirdly, positive discipline model provides inexpensive training and ongoing support so members of communities can teach each other positive discipline skills. The learning process is consistent and sustainable in case of any difficulties confronted by learners in a brand-new challenge. Fourthly, certified trainers across the country who can work with schools and communities. It's reported that demonstration school program is currently being developed based on positive discipline[17]. Chances are that more cooperation can be established for a better work on positive discipline among 
children and adults (including parents, teachers, childcare providers, youth workers, and others).

Advantages of Positive Discipline Model. By going for positive discipline, many people can benefits from this proved efficient method. Children will grow through getting in touch with the positive discipline experience. With positive discipline, children defuse power struggle, learn how to thing, not what to think, build on strengths, not weaknesses, and hold children accountable with their self-respect intact[18]. Millions of parents have come to trust positive discipline for its consistent, commonsense approach to raising happy, responsible kids. As well, positive discipline transforms the way teachers view themselves as the activities in positive discipline show how teaching shifts from head to heart. As yelling begets yelling, hitting begets hitting, parents need to model the types of behavior they want their children to emulate in case of an extreme behavioral flare-up. Teachers are required to focus on controlling themselves other than children learners before working to teach English among 3-4-old preschoolers. It's true that teachers themselves can not only obtain effective social and life skills through experiential activities, but also harvest happy and respectful relationships with young children. Lastly, community as a whole can be bettered with more parents and teachers devoted in positive discipline among children or adult learners. Over years, a climate that maximizes learning will be created and nurtured for people living in it. In a word, benefits can accrue to many people from consistent encouragement and empowerment in positive discipline.

\section{The Impact of Positive Discipline on English Enlightenment among 3-4-year-old Children}

Deep Understanding and Mutual Respect. Understanding and respect are the best investment adults can make in children on English enlightenment. First above, children have their own way of doing things, at times, beyond our understanding and cognition. Teachers are supposed to get into the child's world to discover what works and what doesn't for practical application. It's found that, once there is an understanding behind the behavior, the cause of inappropriate behavior can be removed and no further emotional outbursts will come from the child[19]. There is not always a valid reason behind children's actions and activities, so instructors just try to do the best they can to understand the children. It's especially true in English learning, as the English learning may be stuck in difficulties if insufficient input is given. This includes talking to the children with phrases such as "how does that make you feel?" or "I noticed you looked upset, what happened?", and the like. The identification of the belief behind the behavior of the learning young agents will pay off whilst conducting positive discipline. Furthermore, mutual respect should be established between instructors and learners. Even if instructors are not in support of the idea brought about by learners, adults are expected to work toward greater respect with them. For example, it's normal for kids to explore a new sense of freedom, and that process can sometimes leave parents feeling frustrated. In this case, adults are required to show their kindness by respecting the needs of the child and their firmness by respecting themselves and the needs of the situation. This mutual respect is good for instructors solving various problems in a realistic and respective way.

Effective Communication and Problem Solving Skills. Truly effective parenting or teaching is about connection before correction. Thus how to build stronger bridges of communication between teachers and 3-4-year-old preschoolers, and break the destructive cycles of error and blame in English enlightenment? At the core of the positive discipline approach is to employ non-punitive methods for teaching cognitive skills in a manner that is respectful and encouraging for both learners and teachers. That is, English enlightenment should be delivered in a kind but firm manner, neither permissive nor punitive. Through communicating, learners are reminded that teachers or parents are able and willing to work with them instead of against them, and be on the preschoolers' side. After that, the ineffective communication can be likely to be mended and avoided and honest discussion may be fostered. The strong foundations for healthy communication forged between adults and children can lay groundwork for problem solving. It's argued that addressing early discipline problems is to set children up for success. Whilst solving problems, teachers are supposed to focus on solutions instead of punishment, as involving students in solving problems is much more effective than punishment. In sum, through combating apathy and instilling vital 
problem-solving skills, positive discipline provides possibilities and opportunities where positive change can really take route.

Encouragement instead of Praise. The evidence is overwhelming that encouragement serves more functions and induce more beneficial results than praise and rewards. Then how to encourage children without pampering or praising in English enlightenment? Positive discipline focuses on encouragement and avoids the dangers of praise, as encouragement notices effort and improvement, not just success stressed by praise, so as to build long-term self-esteem and empowerment. Encouragement should celebrate a child's improvements while motivating him to keep trying. Instead of praising kids for a job well done, encouragement stresses on a child's efforts, even if there isn't a successful outcome[20]. Meanwhile, don't bible, and offering a child a reward sends the wrong message. In that case, it seems that the hidden belief behind it is that "If learners don't want to be very good, they have to be paid off". The key is to encourage kids in a way that makes them feel appreciated and recognized, as positive discipline is based on the belief that all kids need to feel a deep sense of belonging. That is, for a better English enlightenment, instructors or parents are supposed to show appreciation for the little things they do or say, things we often overlook. To sum up, learners should be given encouragement to begin to see what they are capable of doing on their own and recognize their full potential in English enlightenment.

\section{Summary}

It has been argued that positive discipline has the potential to change children education landscape across the globe. The fact is evident that positive discipline has gained stream in children education with its unique characteristics and profound impact on learners, instructors and communities. It's advocated that the influence of positive discipline on English enlightenment among 3-4-year-old children be denoted from three areas, i.e., deep understanding and mutual respect, effective communication and problem solving skills, and encouragement instead of praise, so as to raise a child who is responsible, respectful, and resourceful through the process of language enlightenment. It's hoped that this thesis provides a useful reference for English enlightenment practice among young students.

\section{Acknowledgements}

This work is part of the project of On Cultivating and Developing Liaoning Scientific Foreign Language Talents with View to Bourdieu' Theory, the project of On Establishing Generative Mechanism of EFL Autonomous Learning Behaviors and Strengthening Development of Learning Field in Ubiquitous Learning Space, and the project of On Constructing Mechanism and Strategies for College English Autonomous Learning Abilities via Mobile Multimedia. This research was supported by the fund of Liaoning Planning of Philosophy and Social Science (Project No. L16CYY001), the fund of Liaoning Provincial Federation Social Science Circles (Project No. 2017lslktyb-019), and the fund of the Thirteenth Five-Year Plan of Education Sciences of Liaoning Province (Project No. JG16DB013).

\section{References}

[1][2][10]Positive discipline. Retrieved from the information on https : // en. wikipedia. Org /wiki/ Positive_discipline\# Using_Gerunds

[3] Rudolf Dreikurs, Vicki Soltz. Children: The Challenge. Plume, 1964.

[4][7][8]What is Positive Discipline? Retrieved from the information on http://images.shulcloud.com/615/uploads/Resources/what_is_pd_article-1-10.pdf

[5] Jane Nelsen, Lynn Lott. Positive Discipline for Teenagers, Revised 3rd Edition: Empowering Your Teens and Yourself Through Kind and Firm Parenting, Harmony, 2012. 
[6] Jane Nelsen , Lynn Lott , H. Stephen Glenn. Positive Discipline in the Classroom: Developing Mutual Respect, Cooperation, and Responsibility in Your Classroom. Harmony, 2013.

[9] Humanistic education. Retrieved from the information on https: // en. wikipedia. org/wiki/ Humanistic_education

[11] Jane Nelsen, Cheryl Erwin, Roslyn Ann Duffy. Positive Discipline for Preschoolers: For Their Early Years--Raising Children Who are Responsible, Respectful, and Resourceful (Positive Discipline Library). Harmony, 2007.

[12][16][18] Jane Nelsen. Positive Discipline, the classic guide to helping children develop self-discipline, responsibility, cooperation, and problem-solving skills. Ballantine Books, 2006.

[13] [14][15][17] Retrieved from the information on https://www.positivediscipline.com/

[19][20]Bridget Bentz Sizer. Retrieved from the information on http : // www. pbs. Org /parents /talkingwithkids/positive_discipline_tips.html 